\title{
Haemoglobin concentration and linear cardiac output, peripheral resistance, and oxygen transport
}

\author{
M K DANIEL, B BENNETT, AUDREY A DAWSON, J M RAWLES
}

\begin{abstract}
Increasing the haemoglobin concentration results in increased oxygen transport at the cost of increased blood viscosity. This suggested the concept of an optimum packed cell volume for maximising oxygen transport and a study was therefore conducted seeking supportive evidence.

Linear cardiac output was measured as minute distance by Doppler ultrasound in $\mathbf{4 0}$ patients with haemopoietic disorders who had stable haemoglobin concentrations ranging from $\mathbf{3 0}$ to $200 \mathrm{~g} / \mathrm{l}$. The correlation between haemoglobin concentration and minute distance $(r=-0.45 ; p<0.01)$ was negative, and correlations between haemoglobin concentration and mean blood pressure $(r=0.66 ; p<0.001)$ and haemoglobin concentration and peripheral resistance $(r=0.64 ; p<0.001)$ were positive. Calculated oxygen transport increased across the whole range of haemoglobin values.

These results suggest $(a)$ that adjustment of peripheral resistance in response to oxygen availability overrides the influence of blood viscosity on cardiac output and $(b)$ that the optimum packed cell volume for oxygen transport is the highest that can be achieved.
\end{abstract}

\section{Introduction}

There is an intimate relation between the composition of blood and the cardiovascular system. This is especially true for haemoglobin, which after water is the blood's most plentiful constituent. Blood viscosity rises exponentially with increasing haemoglobin concentration, though below the highest packed cell volume commonly encountered $(0 \cdot 60(60 \%)$ or $20 \mathrm{~g} / \mathrm{dl})$ the relation between haemo-

\footnotetext{
Department of Medicine, University of Aberdeen, Foresterhill, Aberdeen AB9 2ZB

M K DANIEL, medical student

B BENNETT, MD, FRCP, reader

AUDREY A DAWSON, MD, FRCP, senior lecturer

J M RAWLES, BSC, FRCP, senior lecturer

Correspondence to: Dr Rawles.
}

globin concentration and viscosity is roughly linear. ${ }^{1}$ In the peripheral circulation the blood flow might be expected to follow Poiseuille's law and be inversely proportional to viscosity. Increasing haemoglobin concentration would then have opposing effects on oxygen delivery, on the one hand increasing oxygen carrying capacity but on the other diminishing blood flow. There may therefore be a haemoglobin concentration that is optimal for oxygen delivery, and it has been suggested that its value approximates to that found in the normal population,,$^{23}$ or is subnormal. ${ }^{4}$

In the central circulation there are several mechanisms by which a low haemoglobin concentration may bring about a change in cardiac output: decreased viscosity leading to a reduction of resistive afterload and increased venous return, hypoxic vasodilatation, hypoxic stimulation of the heart and circulation through the chemoreceptors, and decreased cardiac contractility due to cardiac hypoxia. ${ }^{5}$ An increased haemoglobin concentration, as found in polycythaemia rubra vera, would be expected to have the opposite effects, except that an increase of contractility above normal would not be anticipated. An additional effect of polycythaemia is an increased circulatory volume augmenting venous return. ${ }^{6}$ The net effect of anaemia is to increase cardiac output, ${ }^{78}$ but there are conflicting reports on the effect of polycythaemia, cardiac output being reported as increased ${ }^{6}$ and normal..$^{9-11}$

We have studied 40 patients with haematological disorders who had a wide range of stable haemoglobin concentrations. Our aim was to investigate the relation between cardiac output and haemoglobin concentration and try to define the "optimum packed cell volume." Cardiac output was assessed as a linear measure (minute distance) by a non-invasive Doppler ultrasound technique; this measurement has been discussed elsewhere. ${ }^{12}{ }^{13}$

\section{Patients and methods}

The study group comprised 40 patients attending a haematology ward; table I lists their diagnoses. All were well adjusted to their haemoglobin concentration and those with recent blood loss or transfusion, serious intercurrent illness, a history of cardiac disease, or taking any drug known to affect the circulation or blood pressure were excluded.

Linear cardiac output and blood pressure were measured after 10 minutes' recumbency and before any intervention was started. The velocity of blood flow in the aortic arch was measured with a continuous wave Doppler ultrasound apparatus using a transducer held in the suprasternal notch. ${ }^{14} 15$ 
On line spectral analysis of Doppler shift frequencies was recorded on a paper strip from which stroke distance (systolic velocity-integral) and ventricular rate were measured by planimetry. Linear cardiac output was expressed as minute distance, the product of stroke distance and heart rate. Stroke and minute distances were calculated from an average of 12 beats from each patient. For both stroke and minute distances the within subject cardiac output fully compensates for the reduced oxygen transport then there should be no relation between haemoglobin concentration and oxygen transport. Figure 6 illustrates the positive relation between haemoglobin value and calculated oxygen transport at all concentrations of haemoglobin $(r=0.55 ; p<0.001)$. The rise of cardiac output that occurs in anaemia does not therefore compensate for the reduced oxygen capacity of the blood.

TABLE I-Diagnoses of patients studied

\begin{tabular}{cccccccc}
\hline & Leukaemia & Myeloma & Lymphoma & Other malignancy & Other anaemia & Polycythaemia rubra vera & Total patients \\
\hline No & 19 & 4 & 3 & 5 & 6 & 3 & 40
\end{tabular}

TABLE II-Mean (SD) age, haemoglobin concentration, and haemodynamic measurements in patients with haemopoietic disorders and haemoglobin concentrations above and below $100 \mathrm{~g} / \mathrm{l}$

\begin{tabular}{|c|c|c|c|c|}
\hline & $\underset{(n=40)}{\text { All }}$ & $\begin{array}{l}\text { Haemoglobin }<100 \mathrm{~g} / \mathrm{l} \\
\qquad(\mathrm{n}=21)\end{array}$ & $\begin{array}{l}\text { Haemoglobin }>100 \mathrm{~g} / 1 \\
\qquad(\mathrm{n}=19)\end{array}$ & $\mathrm{p}$ Value \\
\hline Age (years) & $60 \cdot 0(16 \cdot 4)$ & $57 \cdot 7(19 \cdot 1)$ & $62 \cdot 5(12 \cdot 7)$ & NS \\
\hline Haemoglobin $(\mathrm{g} / \mathrm{l})$ & $106(33 \cdot 2)$ & $82(16 \cdot 8)$ & $132(26 \cdot 6)$ & $<0.001$ \\
\hline Systolic blood pressure $(\mathrm{mm} \mathrm{Hg})$ & $122 \cdot 9(18 \cdot 0)$ & $117 \cdot 7(17 \cdot 1)$ & $128 \cdot 5(17 \cdot 7)$ & NS \\
\hline Diastolic blood pressure $(\mathrm{mm} \mathrm{Hg})$ & $65 \cdot 4(12 \cdot 9)$ & $60 \cdot 1(10 \cdot 6)$ & $71 \cdot 2(13 \cdot 0)$ & $<0.01$ \\
\hline Mean blood pressure $(\mathrm{mm} \mathrm{Hg})$ & $84 \cdot 3(13 \cdot 2)$ & $79 \cdot 1(10 \cdot 9)$ & $89.9(13.4)$ & $<0.01$ \\
\hline Stroke distance $(\mathrm{cm})$ & $21 \cdot 6(5 \cdot 99)$ & $23 \cdot 0(6 \cdot 49)$ & $20 \cdot 1(5 \cdot 10)$ & NS \\
\hline Heart rate (beats/min) & $78 \cdot 4(12 \cdot 4)$ & $80 \cdot 3(13 \cdot 6)$ & $76 \cdot 2(10 \cdot 8)$ & NS \\
\hline Minute distance $(\mathrm{cm} / \mathrm{min})$ & $1691(546)$ & $1850(644)$ & $1516(352)$ & NS \\
\hline Linear resistance $(\mathrm{mm} \mathrm{Hg} / \mathrm{m} / \mathrm{min})$ & $5.46(2.06)$ & $4.73(1.67)$ & $6 \cdot 27(2 \cdot 17)$ & $<0.05$ \\
\hline
\end{tabular}

baseline coefficient of variation is about $8 \%$ and the reproducibility about $5 \% .^{16}$

Mean blood pressure was calculated as diastolic pressure plus one third pulse pressure. "Linear resistance," analogous to total peripheral resistance, was calculated as mean blood pressure $\times 100 /$ minute distance.

Oxygen capacity is the product of haemoglobin concentration and $1 \cdot 34$ oxygen transport was calculated as the product of minute distance and oxygen capacity, expressed as $\mathrm{ml}$ of oxygen $/ \mathrm{min} / \mathrm{cm}^{2}$.

Linear and multiple regression analyses were used as appropriate together with unpaired $t$ tests for comparison of means.

\section{Results}

Table II summarises the results for the group as a whole and subdivided into those with haemoglobin concentrations above and below $100 \mathrm{~g} / \mathrm{l}$. The mean haemoglobin concentration was $106 \mathrm{~g} / \mathrm{l}$ with a range of 31 to $197 \mathrm{~g} / \mathrm{l}$ corresponding to packed red cell volumes of 0.09 to 0.62 . Packed cell volume was so closely correlated with haemoglobin concentration $(r=0.99$; $\mathrm{p}<0.001$ ) that these values could be used interchangeably, a haemoglobin concentration of $200 \mathrm{~g} / \mathrm{l}$ being approximately equivalent to a packed cell volume of 0.64

Systolic $(\mathrm{r}=0.51 ; \mathrm{p}<0.001)$, diastolic $(\mathrm{r}=0.66 ; \mathrm{p}<0.001)$, and mean blood pressures $(r=0.66 ; p<0.001)$ each showed a very highly significant positive correlation with haemoglobin concentration (figs 1 and 2 ). Both stroke and minute distances, derived from velocity measurements, showed significant negative correlations with haemoglobin concentrations $(r=-0 \cdot 38$, $\mathrm{p}<0.05$ (fig 3); $\mathrm{r}=-0.45, \mathrm{p}<0.01$ (fig 4)). Pulse rate was not significantly related to haemoglobin concentration.

Since both blood pressure and aortic blood velocity vary with age in the normal population, the relation between blood pressure and aortic blood velocity and haemoglobin concentration might have been spurious had there been a chance association between age and haemoglobin concentration. In our patients, however, there was no statistically significant correlation between age and haemoglobin concentration or between age and blood pressure. Further, age adjustment by multiple regression analysis resulted in only minor adjustments of the regression lines between stroke and minute distances and haemoglobin concentration, well within their $95 \%$ confidence limits, so the figures show the unadjusted regression lines.

Since linear resistance was calculated from mean blood pressure and minute distance, both of which were related to haemoglobin concentration, there was also a very highly significant positive relation between linear resistance and haemoglobin concentration ( $r=0.64, p<0.001$; fig 5).

As haemoglobin concentration falls so does calculated oxygen transport, but cardiac output measured as minute distance goes up. If the increase in

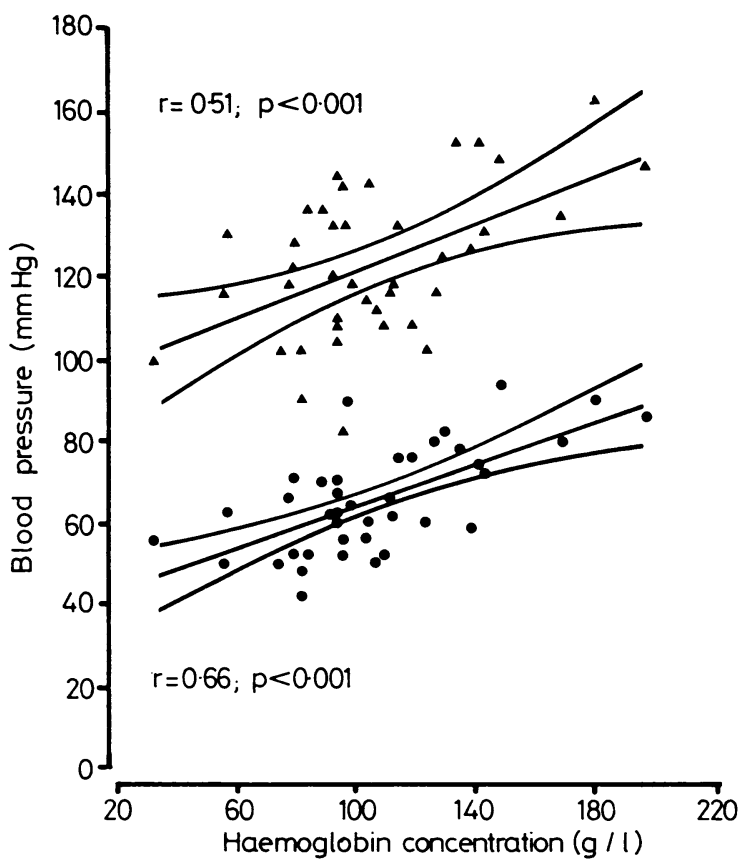

FIG 1-Relation between haemoglobin concentration and systolic $(\boldsymbol{\Delta})$ and diastolic (O) blood pressure. This and figures 2-6 show the regression lines and their $95 \%$ confidence limits.

\section{Discussion}

We have shown that linear cardiac output rises with reduction of haemoglobin concentration in stable clinical conditions, the increase being largely due to a greater stroke distance rather than heart rate, a finding in keeping with previous observations. ${ }^{77}$

Though a low blood pressure in severe anaemia has been reported, ${ }^{18}$ the strong relation between haemoglobin concentration and both systolic and diastolic blood pressure has not been noted before. The rise of blood pressure and fall of cardiac output with increasing haemoglobin concentration reflect an increase in total 
BRITISH MEDICAL JOURNAL VOLUME $292 \quad 5$ APRIL 1986

peripheral resistance, which was itself very highly correlated with haemoglobin concentration. This latter relation was significant in both subgroups, where the slopes of the regression lines were similar, indicating that the mechanism whereby peripheral resistance is altered is operative at both low and high haemoglobin concentrations.

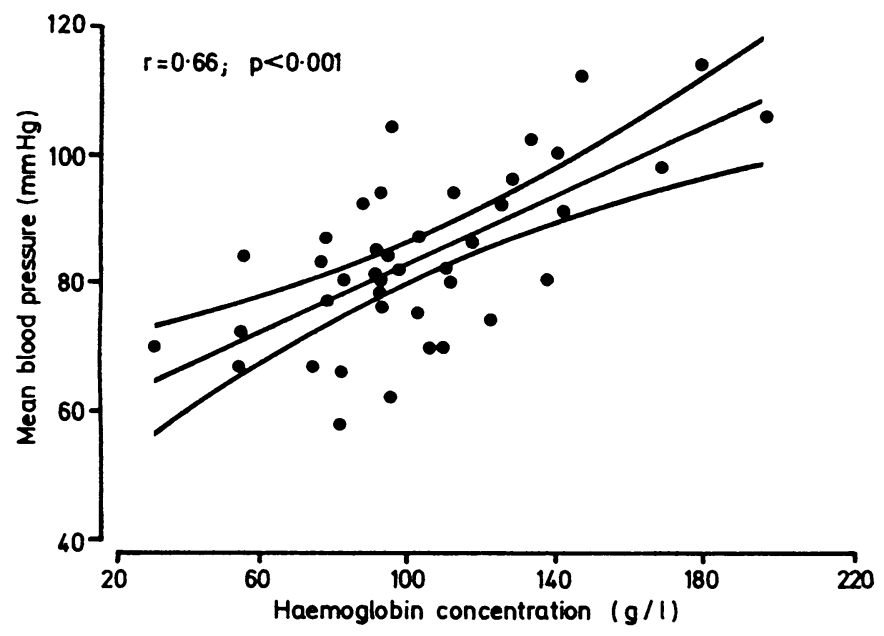

FIG 2-Relation between haemoglobin concentration and mean blood pressure.
Reduced peripheral resistance in anaemia has been noted before. In 24 patients with chronic anaemia systemic vascular resistance was reduced and cardiac index increased, and with treatment of the anaemia these circulatory abnormalities were corrected. ${ }^{17}$ In acute isovolaemic anaemia aortic input impedance was reduced ${ }^{19}$ but blood flow through the peripheral circulation was not uniformly changed, cerebral, coronary, and skeletal muscle blood flow being increased ${ }^{20}$ and renal and cutaneous blood flow reduced. ${ }^{21}{ }^{22}$ In dogs with chronic severe anaemia coronary blood flow was increased by $227 \%$ but renal blood flow rose by only $20 \% .^{23}$ This differential adjustment of territorial blood flow suggests that changes in peripheral resistance are not mediated mechanically by altered viscosity but are part of an integrated response to local and global circulatory needs.

Cerebral blood flow is reduced in polycythaemia, ${ }^{24}{ }^{25}$ in which there is an inverse relation between cerebral blood flow and blood viscosity. ${ }^{26}$ This may be explained by increased viscosity affecting flow according to Poiseuille's law or down regulation of flow in response to increased availability of oxygen. The second seems to be the correct explanation, since there was no significant difference in cerebral blood flow in paraproteinaemic patients with high blood viscosity compared with a matched group of anaemic patients. When blood viscosity was reduced changes in cerebral blood flow were significantly related to changes in arterial oxygen content but not to changes in blood viscosity. ${ }^{27}$

The autonomic nervous system has a key role in these circulatory adaptations to changing haemoglobin concentration and oxygen availability. In dogs reduced arteriolar peripheral resistance is a
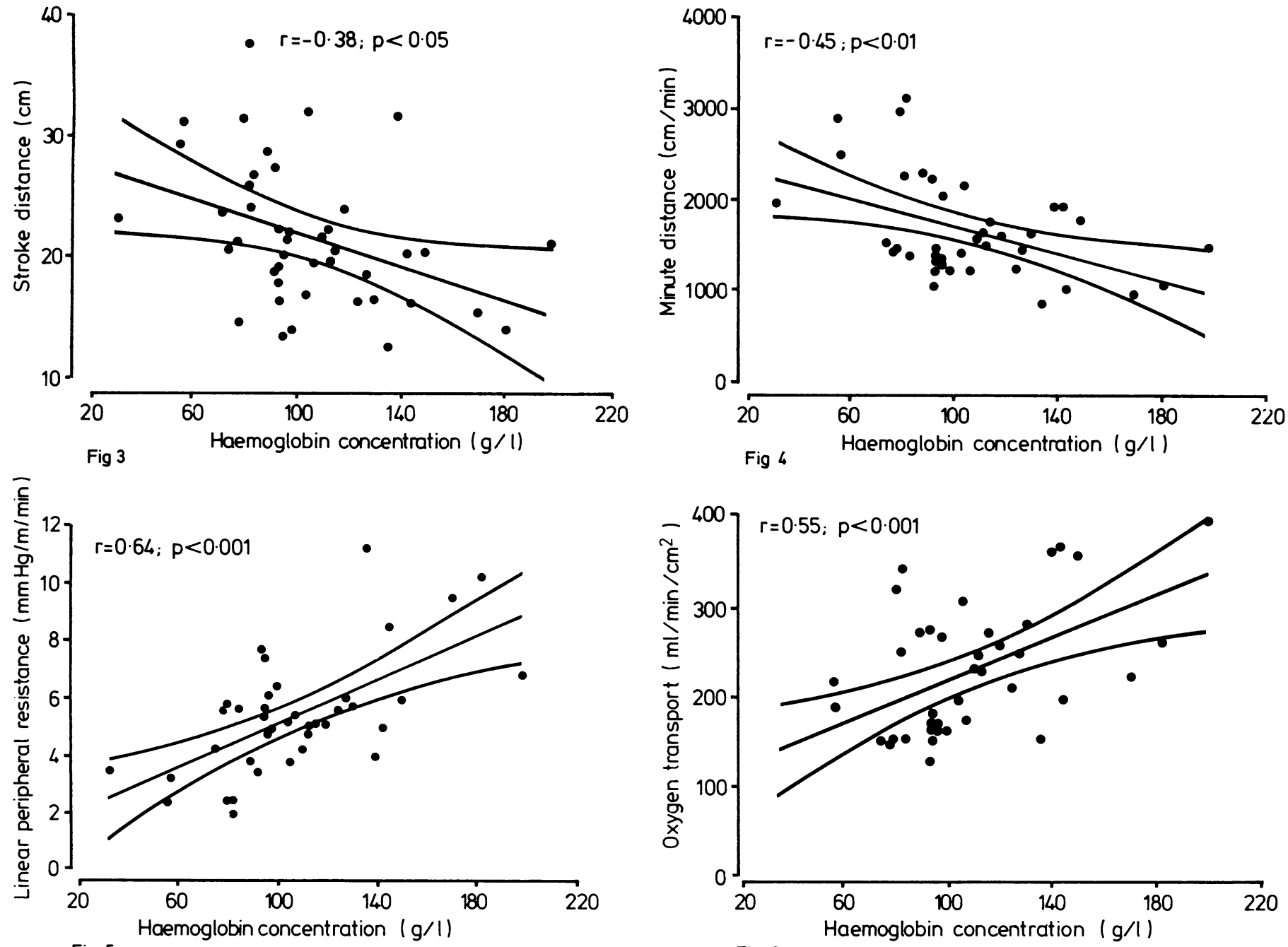

Fig 6

FIG 3-Relation between haemoglobin concentration and stroke distance. FIG 4-Relation between haemoglobin concentration and minute distance. FIG 5 - Relation between haemoglobin concentration and linear resistance. FIG 6-Relation between haemoglobin concentration and oxygen transport. 
reflex autonomic response to tissue hypoxia, ${ }^{28}$ and the rise in cardiac output in response to acute isovolaemic anaemia is significantly less in animals with chronic cardiac denervation than in those with an intact autonomic nervous system. ${ }^{29}$

The concept of an optimum packed cell volume for oxygen transport is based on a consideration of the effect of a change of haemoglobin concentration on flow through a small rigid tube, ignoring the interplay between oxygen availability and autonomic control of the circulation. As noted above, blood viscosity does not itself affect cerebral blood flow in the absence of cerebrovascular disease, and our measurements of cardiac output give no support for the concept applied to the circulation as a whole. Evidence for the concept comes from two studies in patients with peripheral vascular disease. In ischaemic legs blood flow, haemoglobin transport, and (by implication) oxygen delivery all fell with increasing packed cell volume ${ }^{4}$ and healing of diabetic amputations occurred when the haemoglobin concentration was less than $120 \mathrm{~g} / \mathrm{l}$ but not when it was over $130 \mathrm{~g} / 1 .{ }^{30}$ In these patients autonomic control of the circulation may have been ineffective because of autonomic neuropathy or because fixed atheromatous obstructions resulted in the peripheral circulation functioning like a small rigid tube.

Provided that there are no fixed obstructions in the circulation the result of a fall of haemoglobin concentration and oxygen availability is reduction of peripheral resistance leading to increased flow. Our results, however, suggest that this compensatory response is incomplete and that oxygen transport falls with reduction of the haemoglobin concentration. The anaemic patient is potentially further disadvantaged since increased blood flow is associated with a shorter transit time of red cells. Nevertheless, though the arteriovenous oxygen differential is reduced, ${ }^{17}$ the percentage of available oxygen extracted is increase ${ }^{31}$ and total body oxygen consumption remains normal ${ }^{17}$ - though oxygen consumption has been shown to be reduced in the cerebral circulation. ${ }^{20}$

From the point of view of oxygen transport the optimum packed cell volume is therefore the highest that can be achieved, a conclusion reached independently by athletes who train at high altitudes or retransfuse themselves to produce polycythaemia. ${ }^{32}$

MKD was supported by a medical student vacation research grant from the Scottish Home and Health Department. We are grateful to Grampian Health Board for a research grant.

\section{References}

1 Wintrobe MM, Lee GR, Boggs DR, Bithell TC, Athens JW, Foerster J. Clinical hematology. 7th ed. Philadelphia: Lea and Febiger, 1974:970.
2 Guyton AC, Jones CE, Coleman TG. Circulatory physiology: cardiac output and its regulation. Philadelphia: W B Saunders Company, 1973:408.

3 Wintrobe MM, Lee GR, Boggs DR, Bithell TC, Athens JW, Foerster J. Clinical hematology. 7th ed. Philadelphia: Lea and Febiger, 1974:974.

4 Yates CJP, Berent A, Andrews V, Dormandy JA. Increase in leg blood-flow by normovolaemic haemodilution in intermittent claudication. Lancet 1979;ii: 166-8.

5 Guyton AC, Jones CE, Coleman TG. Circulatory physiology: cardiac output and its regulation. Philadelphia: W B Saunders Company, 1973:396-8.

6 Cobb LA, Kramer RJ, Finch CA. Circulatory effects of chronic hypervolemia in polycythemia vera. $\mathcal{f}$ Clin Invest 1960;39:1722-8.

7 Duke M, Ablemann WH. The hemodynamic response to chronic anemia. Circulation 1969;39: 503-15.

8 Brannon ES, Merril AJ, Warren JV, Stead EA. The cardiac output in patients with chronic anemia as measured by the technique of right atrial catheterisation. $\mathcal{J}$ Clin Invest 1945;24:332-6.

9 Liljestrand G, Stenstrom N. Clinical studies of the work of the heart during rest. Acta Med Scand 1925;63:130-41.

10 Altschule MD, Volk MC, Henstell H. Cardiac and respiratory function at rest in patients with uncomplicated polycythemia vera. Am $\mathcal{Y}$ Med Sci 1940;200:478-83.

11 Hovarth SM, Howell CD. Organ systems in adaptation: the cardiovascular system. In: Dill DB, Adolph EF, Wilbur CG, eds. Handbook of physiology. Sect 4. Adaptation to the environment. Washington: American Physiological Society, 1964:153-66.

12 Haites NE, McLennan FM, Mowat DHR, Rawles JM. How far is the cardiac output? Lancet 1985 ;ii: $1025-7$

13 Rawles JM, Haites NE. Doppler ultrasound measurement of cardiac output. Br $\mathcal{H}$ Hosp Med 1984;31:292-7.

14 Mowat DHR, Haites NE, Rawles JM. Aortic blood velocity measurement in healthy adults using a simple ultrasound technique. Cardiovasc Res 1983;17:75-80

15 Haites NE, McLennan FM, Mowat DHR, Rawles JM. Assessment of cardiac output by the Doppler ultrasound technique alone. Br Heart $\mathcal{J}$ 1985;53:123-9.

16 McLennan FM, Haites NE, Mackenzie JD, Daniel MK, Rawles JM. Reproducibility of linear cardiac output measurement by Doppler ultrasound alone. Br Hear f 1986;55:25-31.

17 Roy SB, Bhatia ML, Mathur VS, Virmani S. Hemodynamic effects of chronic severe anemia. Circulation 1963;28:346-56.

18 Stewart HJ, Crane NF, Deitrick JE. Studies of the circulation in pernicious anemia. 7 Clin Invest 1937;16:431-41.

19 Clarke TNS, Prys-Roberts C, Biro G, Foex P, Bennett MJ. Aortic input impedance and left ventricular energetics in acute isovolaemic anaemia. Cardiovasc Res 1978;12:49-55.

20 Heyman A, Patterson LJ, Duke TW. Cerebral circulation and metabolism in sickle cell anemia and other chronic anemias, with observations on the effects of oxygen inhalation. $f$ Clin Invest 1952;31:824-8.

21 Bradley SE, Bradley GP. Renal function during chronic anemia in man. Blood 1947;2:192-202.

22 Abramson DI, Fierst SM, Flachs $\mathrm{K}$. Resting peripheral blood flow in the anemic state. Am Heart $f$ 1943;25:609-12.

23 Vatner SF, Higgins CB, Franklin D. Regional circulatory adjustments to moderate and severe chronic anemia in conscious dogs at rest and during exercise. Circ Res 1972;30:731-40.

24 Ketty SS. Circulation and metabolism of the human brain in health and disease. Am $\mathcal{f}$ Med 1950;8:205-17.

25 Nelson D, Fazekas JF. Cerebral blood flow in polycythemia vera. Arch Intern Med 1956;98: 328-31.

26 Humphrey PRD, Du Boulay GH, Marshall J, et al. Cerebral blood flow in polycythaemia. Lancet 1977;ii:941-3.

27 Brown MM, Marshall J. Regulation of cerebral blood flow in response to changes in blood viscosity. Lancet 1985 ; 1 :604-9.

28 Liang C, Huckabee WE. Mechanisms regulating the cardiac output response to cyanide infusion, a model of hypoxia. $\mathcal{F}$ Clin Invest 1973;52:3115-28.

29 Glick G, Plauth WH, Braunwald E. Role of the autonomic nervous system in the circulatory response to acutely induced anemia in unanesthetised dogs. $\mathcal{I}$ Clin Invest 1964;43:2112-24.

30 Bailey MJ, Johnston CLW, Yates CJP, Somerville PG, Dormandy JA. Preoperative haemoglobin as predictor of outcome of diabetic amputations. Lancet 1979;ii:168-70.

1 Sharpey-Schafer EP. Cardiac output in severe anaemia. Clin Sci 1944:5:125-31.

32 Klein HG. Blood transfusion and athletics. Games people play. N Engl f Med 1985;312:854-6.

(Accepted 3 February 1986)
(1)

\section{YEARS AGO}

"There are a sort of men," says Gratiano in the Merchant of Venice, "whose visages do cream and mantle like a standing pond," and truly there are clinical teachers of this sort. Their clinical lectures are set orations, in which a small nucleus of fact is enveloped in a great cloud of words; they make much use of circumlocutory phrases; they would greatly prefer, for instance, to say that the patient met with his accident while in a condition of inebriety, than bluntly state that he was drunk. They will relate the early history of the patient in the most carefully chosen words, and will dilate upon the most trivial details of the case in neatly pointed sentences; then they will announce their diagnosis with the air of a Prime Minister unfolding his policy, and order a purge with the solemnity of a judge awarding a sentence of penal servitude. They often, however, succeed in presenting a clinical picture which remains in the memory to give their auditors confidence in the hour of need. Moreover, they are often excellent operators, or very successful physicians; their sense of artistic proportion, evidenced by the elegance and elaboration of their diction, finding a congenial field in ordering those minute details of manipulation which contribute so largely to a patient's comfort.

In broad contrast to this class, there is the man, generally to be found among the surgeons, whose boast is that he is a "practical man." Commonly he has a loud voice, and a hearty almost boisterous manner, a considerable command of the more forcible part of the vocabulary, and is always in a hurry. He has generally seen several cases of the kind before, and never fails to tell his class just what to do in all these cases, his great secret being always to do something, expectant treatment finding little favour in his eyes. He is very dogmatic, full of "dodges" and "tips," is generally a "brilliant" operator, has hazy notions about pathology, being particularly careful not to commit himself with regard to the exact nature of any tumour about to be removed, is rather feared than admired by his colleagues, and is always very popular with the students, especially the younger students.

Then there are the teachers who have favourite subjects; the physician who gives elaborate clinical lectures on incurable diseases of the nervous system, the surgeon who has a pet operation which nobody else will take up, or a favourite dressing which other surgeons fail to appreciate. There is, too, the physician who makes a special study of common diseases, and is never so much at home as when demonstrating a case of emphysema or ascites, and, at the opposite pole, the pure specialist who seeks to convince an unwilling audience of the absolute necessity of the routine use of some particular instrument which the average student, and, perhaps too, his senior teachers, imagine to be altogether too complex to understand or to manipulate.

(British Medical fournal 1886;i:353.) 